\title{
Comparison of Low Voltage Cathodoluminescent Phosphors
}

\author{
M. R. Phillips* and D. Drouin**
}

* Microstructural Analysis Unit, University of Technology, Sydney, PO Box 123, Broadway NSW 2007 Australia

** Université de Sherbrooke, 2500 Bd de l'université, J1K 2R1, Sherbrooke, Québec, Canada

Progress in field emission display (FED) technology requires the parallel development of phosphors that exhibit high cathodoluminescence (CL) efficiency at low voltage $(<1 \mathrm{kV})$ excitation and long term CL stability when subjected to high current densities. Five commercial phosphors, $\mathrm{ZnO}: \mathrm{Zn}$, $\mathrm{YSiO}_{5}: \mathrm{Ce}, \mathrm{Y}_{2} \mathrm{O}_{3}: \mathrm{Eu}, \mathrm{SrGa}_{2} \mathrm{~S}_{4}: \mathrm{Ce}$ and $\mathrm{SrGa}_{2} \mathrm{~S}_{4}: \mathrm{Eu}$ have been studied using low voltage scanning cathodoluminescence microscopy and spectroscopy at $300 \mathrm{~K}$. All samples were powders with a 0.5 $-10 \mu \mathrm{m}$ particle size (Figure 1). $\mathrm{ZnO}: \mathrm{Zn}$ was the only specimen that did not display any charging effects at $1 \mathrm{kV}$ when using the in-lens secondary electron image mode, reflecting its good electrical conductivity compared with the other phosphors.

Dominant CL emission peaks were located at 495, 400, 615, 445 and $540 \mathrm{~nm}$ for $\mathrm{ZnO}: \mathrm{Zn}$, $\mathrm{YSiO}_{5}: \mathrm{Ce}, \mathrm{Y}_{2} \mathrm{O}_{3}: \mathrm{Eu}, \mathrm{SrGa}_{2} \mathrm{~S}_{4}: \mathrm{Ce}$ and $\mathrm{SrGa}_{2} \mathrm{~S}_{4}: \mathrm{Eu}$, respectively. Each emission peak was broad except for $\mathrm{Y}_{2} \mathrm{O}_{3}$ :Eu which exhibited a sharp set of emission lines characteristic of Eu ${ }^{3+}$. A similar CL emission intensity was observed from every phosphor when excited under identical conditions at $1 \mathrm{kV}$. CL intensity, $\mathrm{I}_{\mathrm{CL}}$, versus beam current, $\mathrm{I}_{\mathrm{B}}$, measurements revealed that all phosphors displayed a power-law exponent of around $\mathrm{m} \approx 0.8$ with $\mathrm{I}_{\mathrm{CL}} \propto \mathrm{I}_{\mathrm{B}}{ }^{0.8}$ over a wide range of $\mathrm{I}_{\mathrm{B}}, 10$ to $4000 \mathrm{pA}$ (Figure 2). Although a threshold current of around $100 \mathrm{pA}$ was found for $\mathrm{SrGa}_{2} \mathrm{~S}_{4}: \mathrm{Eu}$ (Figure 3).

The emission lifetime for each phosphor was estimated using monochromatic CL images collected at pixel dwell time of $0.125 \mu$ s with frame integration to improve the signal to noise. Monochromatic CL images of $\mathrm{YSiO}_{5}$ :Ce (Figure 4), $\mathrm{ZnO}: \mathrm{Zn}$ (Figure 5) and $\mathrm{SrGa}_{2} \mathrm{~S}_{4}$ : $\mathrm{Ce}$ (not shown) reveal little distortion in the direction of scan, indicating that these phosphors have radiative lifetimes $(\tau)<1 \mu \mathrm{s}$. $\mathrm{SrGa}_{2} \mathrm{~S}_{4}$ :Eu (Figure 6) shows strong smearing indicative of emission lifetimes $\tau<10 \mu$ s whereas gross streaking in $\mathrm{Y}_{2} \mathrm{O}_{3}: \mathrm{Eu}$ (not shown) points to $\tau>100 \mu$ s.

This work has demonstrated the utility of low voltage scanning cathodoluminescence microscopy and spectroscopy for high resolution spatially resolved characterization of the luminescence properties of cathodoluminescent phosphors. 


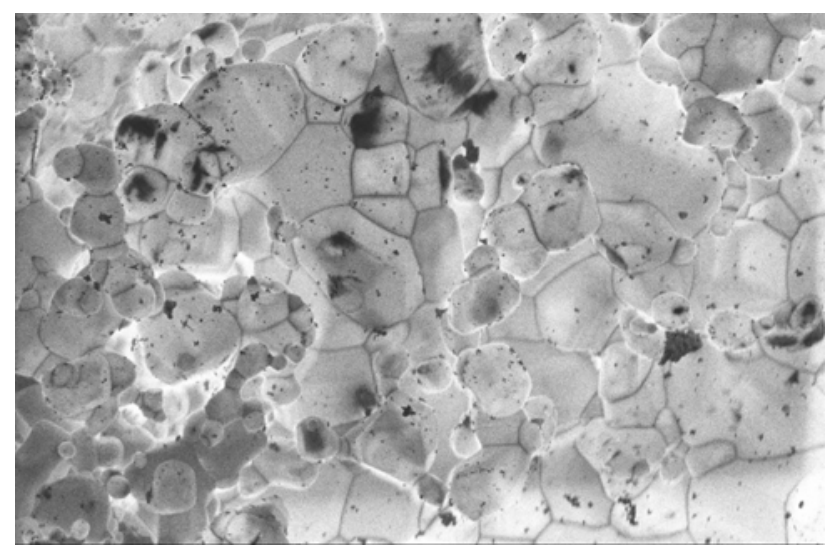

Fig. 1. CL image $\mathrm{ZnO}: \mathrm{Zn}$ at $495 \mathrm{~nm}, 1 \mathrm{kV}$ Horizontal Width of Field $(\mathrm{HWF})=58 \mu \mathrm{m}$

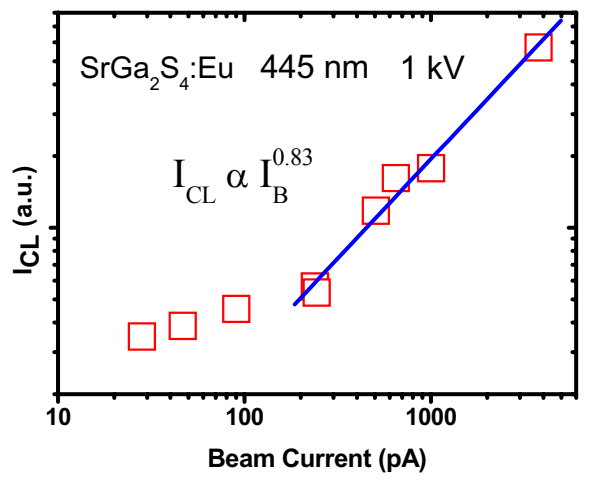

Fig. 3. $\mathrm{I}_{\mathrm{CL}}$ versus $\mathrm{I}_{\mathrm{B}}$ for $\mathrm{SrGa}_{2} \mathrm{~S}_{4}: \mathrm{Eu}$ at $1 \mathrm{kV}$

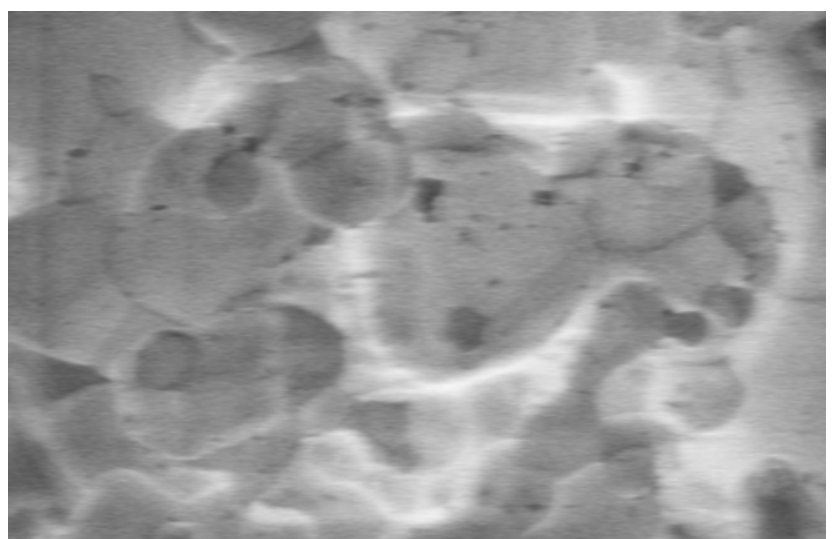

Fig. 5. CL image $\mathrm{ZnO}: \mathrm{Zn}$ at $495 \mathrm{~nm}$ and $1 \mathrm{kV}$ $\mathrm{HWF}=24 \mu \mathrm{m}$, line time $=128 \mu \mathrm{s}$

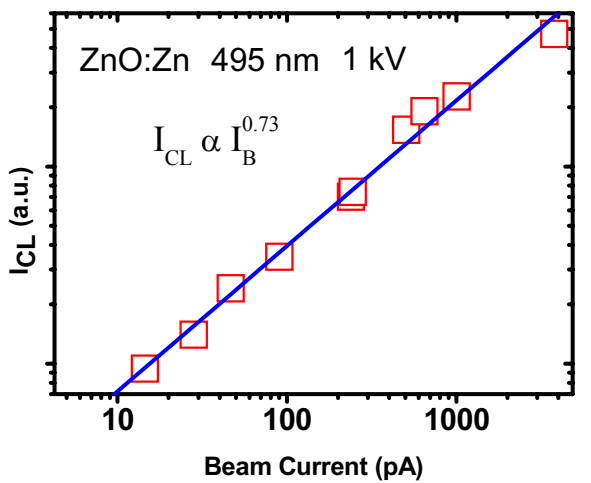

Fig. 2. $\mathrm{I}_{\mathrm{CL}}$ versus $\mathrm{I}_{\mathrm{B}}$ for $\mathrm{ZnO}: \mathrm{Zn}$ at $1 \mathrm{kV}$

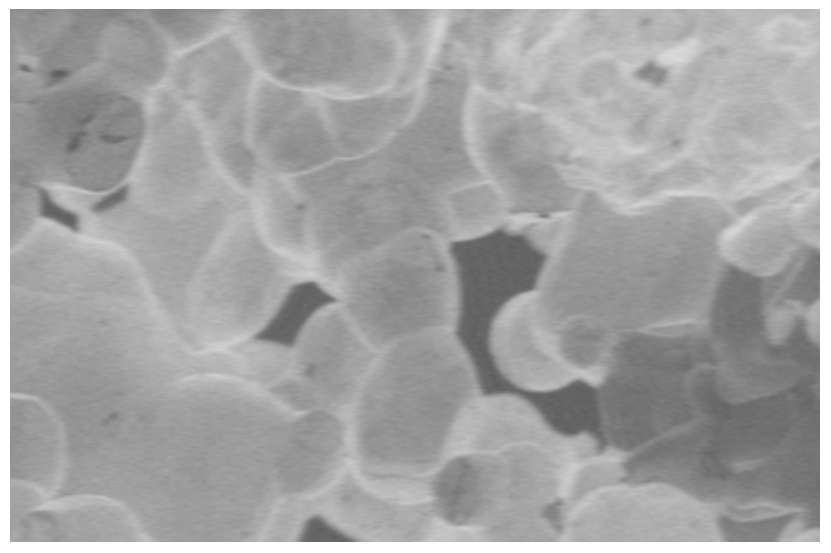

Fig. 4. CL image $\mathrm{SrGa}_{2} \mathrm{~S}_{4}$ :Ce at $445 \mathrm{~nm}$ and $1 \mathrm{kV}, \mathrm{HWF}=24 \mu \mathrm{m}$, line time $=128 \mu \mathrm{s}$

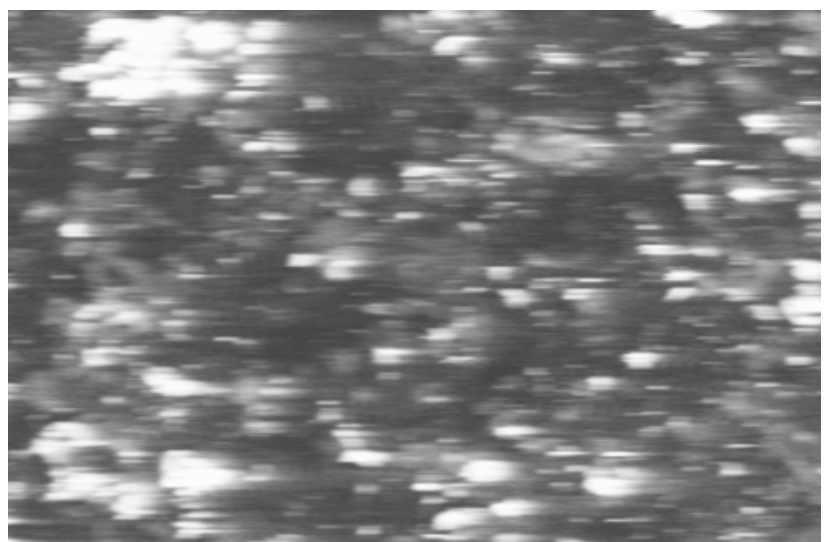

Fig. 6. CL image $\mathrm{SrGa}_{2} \mathrm{~S}_{4}: \mathrm{Eu}$ at $540 \mathrm{~nm}$ and $1 \mathrm{kV}, \mathrm{HWF}=58 \mu \mathrm{m}$, line time $=128 \mu \mathrm{s}$ 